\title{
Increasing the Chances of Natural Conception: Opinion Statement from the the Brazilian Federation of Gynecology and Obstetrics Associations - FEBRASGO - Committee of Gynecological Endocrinology
}

\section{Aumentando as chances de concepção natural: Parecer da Comissão Nacional de Ginecologia Endócrina da Federação Brasileira das Associações de Ginecologia e Obstetrícia}

\author{
Bruno Ramalho de Carvalho ${ }^{10}$ Ionara Diniz Evangelista Santos Barcelos ${ }^{2}$ \\ Sebastião Freitas de Medeiros ${ }^{3}$ Cristina Laguna Benetti-Pinto ${ }^{4}$ Daniela Angerame Yela ${ }^{4}$ \\ Andrea Prestes Nácul ${ }^{5}$ Gustavo Arantes Rosa Maciel ${ }^{6}$ José Maria Soares Júnior ${ }^{6}$ \\ Ana Carolina Japur de Sá Rosa e Silva ${ }^{7}$ Laura Olinda Bregieiro Fernandes Costa ${ }^{8}$
}

\footnotetext{
${ }^{1}$ BONVENA - Medicina Reprodutiva, Brasília, DF, Brazil

2 Department of Gynecology and Obstetrics, Universidade Estadual do Oeste do Paraná, Cascavel, PR, Brazil

3 Department of Gynecology and Obstetrics, Faculdade de Medicina, Universidade Federal do Mato Grosso, Cuiabá, MS, Brazil

${ }^{4}$ Department of Tocogynecology, Faculdade de Ciências Médicas, Universidade Estadual de Campinas, Campinas, SP, Brazil

${ }^{5}$ Hospital Fêmina, Grupo Hospitalar Conceição, Porto Alegre, RS, Brazil

${ }^{6}$ Department of Gynecology and Obstetrics, Faculdade de Medicina de São Paulo, Universidade de São Paulo, São Paulo, SP, Brazil

7 Department of Gynecology and Obstetrics, Faculdade de Medicina de

Ribeirão Preto, Universidade de São Paulo, Ribeirão Preto, SP, Brazil

${ }^{8}$ Faculty of Medical Sciences, Universidade de Pernambuco, Recife, PE, Brazil

Rev Bras Ginecol Obstet 2019;41:183-190.
}

\begin{abstract}
Address for correspondence Bruno Ramalho de Carvalho, MD, MSc, BONVENA - Medicina Reprodutiva, SGAS 614, Conjunto C, Salas 177/179/181/182 VITRIUM - Centro Médico Inteligente Asa Sul, 70200-740, Brasília, DF, Brazil (e-mail: ramalho.b@gmail.com).
\end{abstract}

\begin{abstract}
Keywords

- natural fertility

- fertility determinants

- fecundability

- reproductive period

- preconception care

Considering that myths and misconceptions regarding natural procreation spread rapidly in the era of easy access to information and to social networks, adequate counseling about natural fertility and spontaneous conception should be encouraged in any kind of health assistance. Despite the fact that there is no strong-powered evidence about any of the aspects related to natural fertility, literature on how to increase the chances of a spontaneous pregnancy is available. In the present article, the Brazilian Federation of Gynecology and Obstetrics Associations (FEBRASGO, in the Portuguese acronym) Committee on Endocrine Gynecology provides suggestions to optimize counseling for non-infertile people attempting spontaneous conception.
\end{abstract}

(1) Bruno Ramalho de Carvalho's ORCID is https://orcid.org/0000-

0002-1554-9499.

received

November 9, 2018

accepted

December 5, 2018

published online

February 15, 2019
DOI https://doi.org/

10.1055/s-0039-1677838.

ISSN 0100-7203.
Copyright $\odot 2019$ by Thieme Revinter

Publicações Ltda, Rio de Janeiro, Brazil
License terms

(c) (i) 


\author{
Resumo \\ Palavras-chave \\ - fertilidade natural \\ - determinantes de \\ fertilidade \\ - fecundabilidade \\ - período reprodutivo \\ - cuidados pré- \\ concepcionais
}

Uma vez que mitos e equívocos sobre a procriação natural se espalham rapidamente na era do fácil acesso à informação e às redes sociais, o aconselhamento adequado sobre a fertilidade natural e a concepção espontânea deve ser encorajado em qualquer tipo de assistência à saúde. Apesar do fato de não haver evidências fortes sobre qualquer dos aspectos relacionados à fertilidade natural, existe literatura sobre como aumentar as chances de uma gravidez espontânea. No presente artigo, a Comissão Nacional de Ginecologia Endócrina da Federação Brasileira das Associações de Ginecologia e Obstetrícia (FEBRASGO) oferece sugestões para otimizar o aconselhamento a pessoas que tentam a concepção espontânea, na ausência do diagnóstico de infertilidade.

\section{Introduction}

Doctors in any specialty and any other health professionals must be encouraged to provide adequate counseling about sexual and lifestyle habits that may be related to natural fertility and spontaneous conception.

There are many myths and misinterpretations of information regarding the optimization of the chances of natural procreation. The easy access to information and to social networks today allows distorted concepts to spread with enormous rapidity, causing a commotion of immeasurable impact, and even confusing health professionals.

In fact, to date, there are no strong-powered studies in any aspect related to natural fertility, so the current knowledge is insufficient to support definitive recommendations. However, the available literature, based on consensual expert opinion, provides suggestions for counseling patients about how they should increase the chances of having a spontaneous pregnancy.

In the present article, we provide subsidies to overthrow myths and misconceptions in the daily routine of reproductive counseling, based on the best evidence available.

\section{The Impact of Female Age}

Advances in knowledge and better access to information on healthy living habits cause a great confusion between the concepts of youth and joviality. From the dissociation of those concepts, appears the idea that people at the age of 40 years old today are as healthy as those who were 20 or 30 years old in the past-or even healthier. Unfortunately, regarding female fertility, time exerts many changes on reproductive function; thus, although a woman may look and feel good in her 40s, her fertility is not the same as that of a woman in her 30s.

The statistics are not unanimous, but recent data indicate that cumulative pregnancy rates after 12 cycles of attempt range from almost $80 \%$ at the age between 25 and 27 years old to $55 \%$ at the age between 40 and 45 years old. ${ }^{1}$ As it happens, pregnancy rates have been invariable, at least in the last three decades. ${ }^{2}$

There is a plausible biological explanation for the decline in human fecundability with increasing female age: the decrease in the quantity, in the quality, and in the reproductive potential of the eggs. At birth, the number of eggs in both ovaries is in the millions, but at the beginning of puberty, women have only hundreds of thousands, which will be consumed over the 400 or so ovulatory cycles in their reproductive lives. It is believed that around the age of 38 years old, there is a significant acceleration of egg consumption, and although much is discussed about the 35-year-old frontier, the interval between 37 and 38 years old is probably the most significant in terms of loss of female reproductive potential. ${ }^{3,4}$

According to the mathematical model published by Habbema et al (2015), ${ }^{5}$ the chances of a couple to realize the desired family size can be estimated from the age of the woman when initiating pregnancy attempts. It predicted that couples with a desire to have only one child would have a $90 \%$ chance of spontaneous pregnancy if attempts were initiated until the woman reached 32 years old. However, when the goal of the couple was to naturally conceive two or three children, the woman should initiate attempts at the ages of 27 and 23 years old, respectively, at the risk of failing to reach the intended offspring. ${ }^{5}$

Therefore, considering that the probability of conception is highly dependent on maternal age, the impact of modern lifestyle and delaying childbearing can decrease the likelihood of successful spontaneous conception.

\section{The Impact of Male Age}

As it has been observed for women, there is a tendency for increased paternal age in the reproductive function in developed countries, and more attention has been paid to the effects of age on this function. ${ }^{6}$ The association between male age and reproductive potential for natural conception is little known, but is becoming an emerging issue.

The mathematical model published by Dunson et al $(2002)^{7}$ highlighted the negative impact of male age on the chances of spontaneous pregnancy when women $\geq 35$ years old had sexual partners at least 5 years older, but there is no doubt that in these cases the age of the woman becomes a confounding factor. In parallel, in a recently published study from the USA, male age adjusted for female age was not associated with fecundability, although the number of men $>45$ years old was small. ${ }^{1}$

With the evidence available to date, there is no data to support or rule out such an association, but there are clear indications of the negative effect of advanced paternal age on 
seminal parameters, ${ }^{8,9}$ such as the amount of produced sperm cells and their motility, ${ }^{10}$ and an increased risk of genetic, neurological, and psychiatric diseases in the offspring is also observed. ${ }^{8} \mathrm{~A}$ recent meta-analysis of 81 studies found some evidence of the association between paternal age and problems such as autism, autism spectrum disorders, schizophrenia, stillbirth, birth defects, and aneuploidies. ${ }^{11}$

\section{The Mathematical Model for Fertility Window}

It is easy to understand why people believe in maximum female fertility on the day of ovulation, and it is still very common to see people holding intercourses for a day or two beyond that date in the belief that there is still fertility. However, with the support of the American Society for Reproductive Medicine (ASRM) and of the Society for Reproductive Endocrinology and Infertility, ${ }^{12}$ mathematical models define the fertile period as a window that begins five days before ovulation and ends on the day it happens. Furthermore, it is assumed that the greater chance of natural pregnancy is associated with coitus occurring two days before ovulation, and this chance decreases as coitus distances from this point $(\mathbf{- F i g . 1} \mathbf{1}){ }^{7}$ Thus, the chances of natural conception are greatest over a period of 6 days ending on the day of ovulation; on the other hand, although one cannot speak of impossibility, chances of conception are very low outside this interval.

Signs of ovulation can also be used for counseling on natural fertility, especially when it is not possible to identify the fertile period based on the duration of the cycle or when the comprehension of the mathematical model is not reached by the couple. The signs of easier identification are the filamentous mucus or type 4 mucus-elastic, slippery and transparent - , and the elevation of basal temperature, but both behave as expected in only $\sim 60 \%$ of the cycles ${ }^{13,14}$ and, therefore, will not always be effective in predicting the fertile window.

Finally, it should be noted that the fertile period does not change with the advancement of the age of the woman; the chance of conception is what diminishes with aging. Thus, with isolated intercourse 2 days before ovulation, the chance of pregnancy in a woman between the ages of 35 and 39 years old corresponds to approximately half the chance of a woman $<26$ years old. ${ }^{7}$

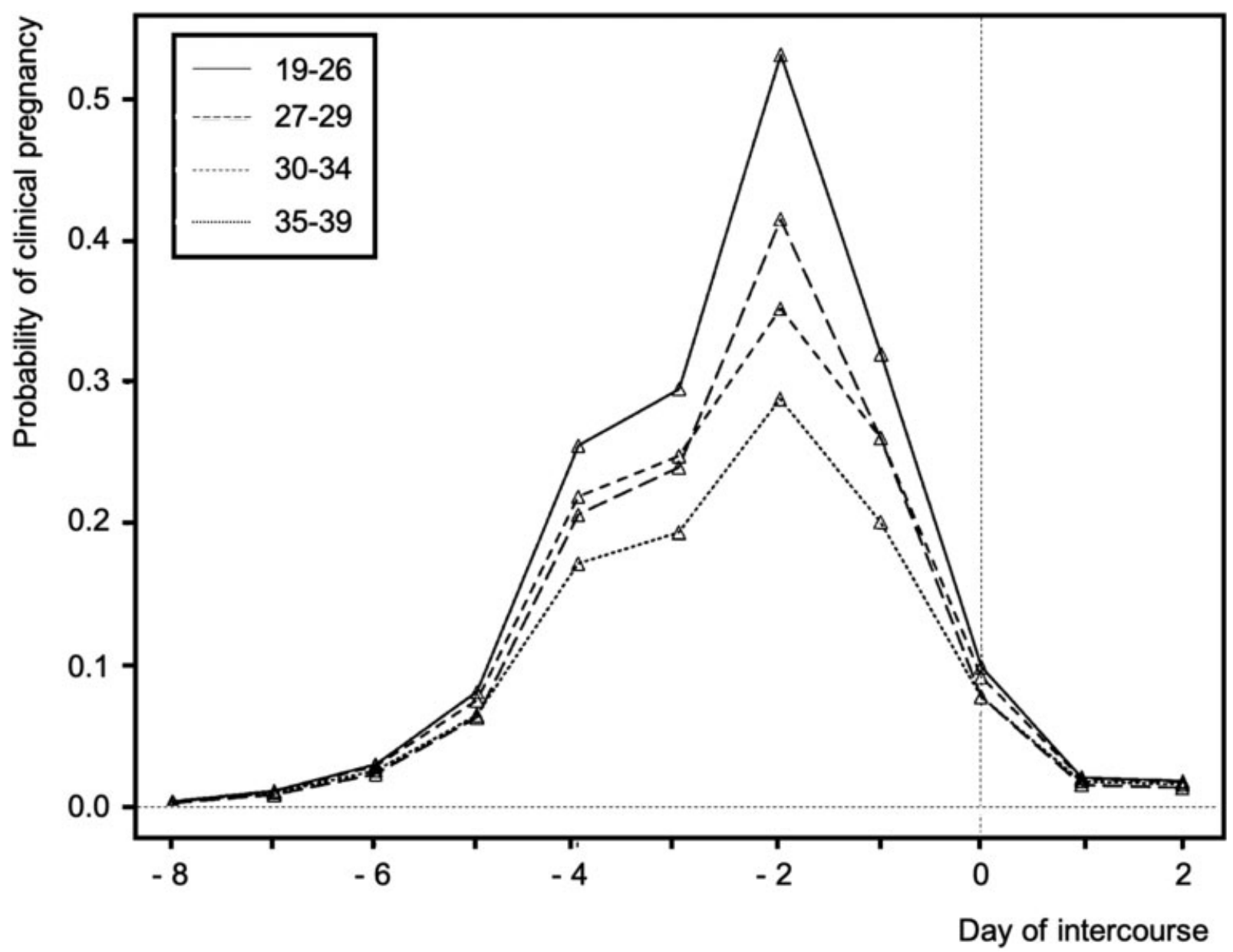

Fig. 1 Probability of clinical pregnancy following intercourse on a given day in relation to ovulation, for women of average fertility, aged 19-26, 27-29, 30-34 and 35-39 years old (data were drawn from the European Study of Daily Fecundability, including 433 pregnancies), adjusted for the age of the male partner (Dunson et al, 2002). ${ }^{7}$ This figure has been reprinted with permission from Oxford University Press on behalf of the Brazilian Federation of Gynecology and Obstetrics Associations (FEBRASGO, in the Portuguese acronym) Committee on Endocrine Gynecology, for publication on FEBRASGO's official journal, RBGO Gynecology and Obstetrics. 


\section{The Common Practice of Coitus Every Other Day}

The information that one could have a greater chance of conception if the practice of coitus occurs every other day is very common, considering a misperception that frequent ejaculations could lead to a diminished number of sperm count. However, a retrospective study that analyzed nearly 10,000 semen specimens observed that, in men with normal semen quality, sperm concentrations and motility remain normal, even with daily ejaculation. Interestingly, in men with oligozoospermia, sperm concentration and motility may be highest with daily ejaculation. ${ }^{15}$ In one study involving 221 presumably fertile couples planning to conceive, the highest cycle fecundability (37\% per cycle) was associated with daily intercourse. ${ }^{16}$

In spite of the varied quality of existing studies, evidence suggests that reducing the ejaculatory abstinence period may positively influence semen quality based on a consistent trend toward an increase in the percentage of motile, progressively motile and rapid spermatozoa with shorter abstinence periods. ${ }^{17}$ Therefore, shortening the abstinence period may be a potential strategy to improve sperm quality, ${ }^{18}$ while longer intervals are associated with lower pregnancy rates. Although evidence suggests that daily intercourse may confer a slight advantage, specific recommendations regarding the frequency of intercourse may unnecessarily induce stress. Couples should be advised that the optimal frequency of intercourse is best defined by their own preference. ${ }^{12}$

\section{The Positions Adopted for Intercourse}

The positions adopted for intercourse or how women remain after coitus have no association with improved chances of pregnancy. There is no need for any postcoital routine, and although many women believe that remaining in a supine position for an interval period after intercourse facilitates sperm transport and prevents leakage of semen from the vagina, this belief has no scientific foundation. ${ }^{12}$

Some studies have demonstrated that rapid sperm transport through the female genital tract is passive and is provided by uterine contractions. Using hysterosalpingoscintigraphy, rapid sperm transport was studied by placing technetiumlabeled albumin macrospheres of sperm size at the external cervical os. The ascension of the macrospheres occurred immediately following deposition at the external os of the cervix. As early as 1 minute thereafter, the macrospheres had reached the intramural and isthmical part of the tube. ${ }^{19}$ Another study has documented that within 15 minutes after the coitus, a constant level of sperm exists in the oviduct. ${ }^{20}$ Still regarding intercourse, the presence or absence of female orgasm does not seem to alter the probability of conception. ${ }^{12}$

\section{The Use of Intimate Lubricants}

Many couples trying to conceive require a coital lubricant when suffering from vaginal dryness or discomfort during intercourse. However, there is much uncertainty regarding the ideal fertility-preserving coital lubricant. ${ }^{21}$ Couples are faced with a great number of options and are often worried whether the use of these substances might compromise their chance to achieve pregnancy. ${ }^{22}$ Multiple lubricants have been shown in multiple studies to adversely affect sperm motility at a variety of concentrations. ${ }^{23-27}$ One study showed sperm to be immotile after 15 minutes of exposure to these lubricants. ${ }^{24}$ Since vaginal lubricants have been shown to affect sperm motility in vitro, it is possible that lubricant use during intercourse may negatively affect natural fertility by inhibiting fertilization. ${ }^{4,21}$ These findings reaffirm the notion that not all coital lubricants and oils are alike, and that individual lubricants and oils must be carefully evaluated regarding their effects on fertility.

A recent study has addressed this issue and evaluated the effects of coital lubricants and oils on sperm motility. Changes in total and progressive motility were variable for sperm incubated under different oils. Both total and progressive sperm motility slightly decreased after exposure to canola and baby oils; however, this decrease was not significant. After the initial decrease, sperm motility remained stable at high levels within up to 60 minutes of incubation. This slight drop in motility is understandable and can be attributed to the adjustment of sperm to a new microenvironment. It was not observed a negative impact of canola and baby oils on sperm motility. This result was attributed to the presence of nontoxic ingredients in these oils. Sesame and mustard oils were incorporated into the study due to the lack of information regarding their effects on sperm. Sesame oil showed an immediate drastic decline in both total and progressive sperm motility within 5 minutes of incubation. Sperm motility continued to decline nonsignificantly over the course of incubation under sesame oil. In contrast, exposure of sperm to mustard oil initiated hyperactive motility and the sperm remained hyperactive during the entire incubation period without any decline in motility. ${ }^{22}$

The coital lubricants and oils that were found to have negative effects on sperm motility should be avoided. Therefore, when suffering from vaginal dryness or discomfort during intercourse, canola, baby or mustard oil should be preferred, as they appear to not affect significantly sperm motility.

\section{Is it Possible to Define the Gender of the Baby on the Day of Ovulation?}

Common popular belief states that intercourse closest to the day of ovulation would favor the conception of boys, and that intercourse more distant from the time of ovulation would favor the conception of girls. Even though this is such a strong belief, limited and controversial evidence is currently available.

A recent study indicates that when comprehensive instruction is provided, the gender of a child can be preselected with a high degree of confidence by timing coitus, using the Post-Peak approach of Billings Method for males and Pre-Peak for females. ${ }^{28}$ Another study evidenced that the gender ratio favored males when intercourse preceded ovulation/fertilization by two days or longer. While this association was statistically significant, the number of pregnancies involved was too small to conclude that the relationship is real. ${ }^{29}$ 
On the other hand, a prospective study of 33 pregnancies using the rise in luteinizing hormone in the early morning urine, the peak cervical mucus symptom, and the shift in basal body temperature as indicators of ovulation clearly refuted the theory that intercourse close to ovulation favors the conception of males. ${ }^{30}$

For routine application, timing sexual intercourse to determine the gender of the baby may not be part of the counseling strategy, ${ }^{16,31}$ since there is no strong evidence of a real connection. In reality, there is a small number of studies, most of them performed more than 15 years ago, in small groups of patients, and showing contradictory results that do not support a consensual position.

\section{Diet and Female Fertility}

There is scarce good scientific data relating diet and fertility, and the real benefits of vegetarian or low-fat diets, or of the intake of multivitamins, antioxidants or herbal supplementation, are not consensual. ${ }^{12}$

Among specific micronutrients, folic acid and vitamin D seem to be the most studied, but robust evidence in the literature is still lacking. ${ }^{32}$ Observational studies suggested an association between folic acid intake and a reduced risk of spontaneous miscarriage among women attempting pregnancy or during its early weeks, especially if the intake levels were above those recommended for the prophylaxis of neural tube defects. ${ }^{33-35}$ Also, folic acid consumption appeared to be related to a reduction in the risk of annovulation $^{36}$ and should be related to a shorter time to pregnancy. ${ }^{37}$ Vitamin D status or its supplementation, by the way, is poorly associated with annovulation, probability of conception, time to pregnancy, or pregnancy losses. $^{38-41}$

In a large preconception cohort, trans fat intake was associated with reduced fecundity, and consumption of omega-3 polyunsaturated fatty acids was associated with higher fecundity in the absence of fish oil supplementation; in fact, these associations were found only in American women, and these effects were not found in Danish women, although the intake amount among Danish women varied from low to rare. ${ }^{42}$

In a cohort of 17,544 women without a history of infertility who were followed-up for 8 years, those who had the greatest intake of protein from vegetables, full-fat dairy food, iron, and monounsaturated fats during the preconception period had significantly higher chances of becoming pregnant when compared with women with different diet patterns, controlling for age, body mass index (BMI), alcohol and coffee consumption, smoking, and use of oral contraceptives. ${ }^{43}$

A possible decrease in the risk of anovulatory infertility was observed in the regular intake of multivitamin supplements, ${ }^{36}$ the replacement of animal protein for vegetable sources of protein, ${ }^{44}$ lower carbohydrate intake and dietary glycemic load, ${ }^{45}$ and preconception intake of high amounts of whole grains. ${ }^{46}$

Finally, dietary habits have also been investigated for reproductive effects. Excessive caffeine consumption (over
5 cups of coffee per day) may decrease fertility, ${ }^{12}$ but the 8 year follow-up of 18,555 married women did not support a causal relation between alcohol or caffeine intake and decreased fertility. In the same cohort, the association between soft drinks and anovulatory infertility could not be related to caffeine or sugar content. ${ }^{47}$

In summary, current limited evidence on the reproductive effects of diet supports benefits from folic acid supplementation before and during early pregnancy, low dietary glycemic load and consumption of high amounts of whole grains, higher intake of omega-3 polyunsaturated fatty acids, lower intake of trans fatty acid, and fish as a source of animal protein.

\section{Diet and Male Fertility}

Since the early 1980s, several nutrients and components have been considered as possible determinants of sperm function, fertility, or of normal function of the reproductive system. ${ }^{48}$ Accumulating evidence from human in vitro and animal studies indicates that male obesity and some components of the diet may play an important role in modulating spermatogenesis, sperm maturation, and fertilizing ability. For example, male obesity has been related to impaired fertility because of its effect on the molecular and physical structure of sperm. ${ }^{49-51}$

Moreover, several components of the diet that have been associated with an increased risk of obesity, of insulin resistance, and of diabetes have also been related to low sperm quality or function in animal models. For example, diets rich in trans-fatty acids, saturated fats ${ }^{52}$ or cholesterol ${ }^{53}$ have been associated with testicular disruption, involving impairments in spermatogenesis, potentially affecting male fertility and the offspring in rats and rabbits. Testicular metabolic alterations induced by high-calorie diets may also lead to mitochondrial dysfunction, which is closely associated to reactive oxygen species (ROS) overproduction and oxidative stress. Reactive oxygen species easily targets spermatozoa DNA and lipids, contributing to decreased sperm quality. ${ }^{54}$

On this particular subject, we have very low-quality randomized controlled trials, conducted in small samples of participants, investigating the effect of specific nutrients and of nutritional supplements on male infertility. ${ }^{55}$ However, in spite of the lack of proper evidence about the role of diet in sperm parameters and about the effectiveness of supplements to combat male infertility, there has been an invasion of integrative dietary products in the last two decades in some assisted reproductive technology (ART) clinics. Unfortunately, the safety of these dietary supplements has not been tested, and the dangers for the user population are unknown. ${ }^{56}$

Although based on epidemiological observational design studies, which limits the ability to determine causality between the intake of food and nutrients and the parameters of semen quality and fecundability, a recent and extensive review indicated that healthy diets rich in some nutrients such as omega-3 fatty acids, some antioxidants (vitamin E, vitamin $C, \beta$-carotene, selenium, zinc, cryptoxanthin, and 
lycopene), other vitamins (vitamin D and folate), and low in saturated fatty acids and trans-fatty acids were inversely associated with low semen quality parameters. ${ }^{56}$

Fish, shellfish and seafood, poultry, cereals, vegetables and fruits, low-fat dairy and skimmed milk were positively associated with several sperm quality parameters. However, diets rich in processed meat, soy foods, potatoes, full-fat dairy and total dairy products, cheese, coffee, alcohol, sugarsweetened beverages and sweets have been detrimentally associated with the quality of semen in some studies.

In summary, as far as fecundability is concerned, a high intake of alcohol, caffeine, red meat and processed meat by males has a negative influence on the chances of pregnancy or on the fertilization rates in their partners. ${ }^{56,57}$ On the other hand, regular consumption of fish and seafood, poultry, cereals, vegetables and fruits, and low-fat dairy products can improve seminal parameters.

\section{The Impact of Smoking}

Smoking has a negative impact on the overall health of men and women, which may include the reproductive function. Scientific research on the subject suggests that smoking may lead to a decline in the natural fertility of women and men. ${ }^{58-61}$

The literature demonstrates decreased chances of pregnancy, increased spontaneous miscarriage rates, and earlier onset of menopause in smoking women when compared with non-smokers. ${ }^{12,62-65}$

In smoking men, semen quality maybe impaired by a decrease in sperm count, an increase in malformed gametes, and possible aggression to sperm DNA. ${ }^{12,63-65}$

It must be stressed that there are no large-scale, randomized, clinical trials examining the effect of cigarette smoking on fertility. Even though scientific unanimity is not obtained, the data accumulated to date support the value of the preventive approach to infertility, and for this reason, discourage smoking or exposure to smoking for men and women attempting pregnancy, ${ }^{66}$ even when ART is recommended. ${ }^{67}$

\section{Tests for Measuring Fertility among Non- infertile Women}

The cumulative probability of conception and the relative probability of conception in a given menstrual cycle (fecundability) were prospectively evaluated in 750 women without a history of infertility; low serum antimüllerian hormone (AMH) or high follicle-stimulating hormone (FSH) levels were not associated with reduced fertility in at least the following 12 cycles of attempt, even after controlling for age, race, BMI, smoking status, and recent use of hormonal contraceptives. ${ }^{68}$

In a recent multicenter cross-sectional study, no differences in serum AMH and antral follicle count (AFC) were found between healthy normo-ovulatory women with unexplained infertility and women not seeking treatment for fertility, even after controlling for personal confounders or study site. ${ }^{69}$
Finally, other recent studies had already demonstrated that AFC and AMH levels did not differ between fertile and infertile women of the same age, ${ }^{70,71}$ and that spontaneous pregnancy may occur even in women presenting low AMH or AFC levels, or high FSH levels. ${ }^{72,73}$

In the light of the current knowledge, ovarian reserve tests cannot be parameters for inferences about the reproductive potential in the medium or long term. Thus, they cannot be decisive for women to postpone maternity or not, and there is no indication to include ovarian reserve evaluation as a clinical routine for young women attempting to get pregnant, even if they had never been mothers, since they may not predict natural fertility alone, neither currently nor in the future.

There is still much knowledge to be obtained regarding natural fertility. An increasing amount of data have been associating the exposure to environmental pollutants, toxicants, marijuana and other recreational drugs, and jobrelated exposures (microwaves, heat, pesticides and other chemicals, for example) with reduced fecundability and infertility. $^{12}$

Finally, observational studies have suggested that stress, frequent in the present days, is associated with infertility. However, no clinical trial has demonstrated definitely that reducing stress prior to infertility treatment improves pregnancy rates. Attempts to isolate single causal links between stress and infertility have not yet been successful due to their multifaceted etiologies. ${ }^{74}$

Conflicts of Interest

The authors have no conflicts of interests to declare.

\section{References}

1 Wesselink AK, Rothman KJ, Hatch EE, Mikkelsen EM, Sørensen HT, Wise LA. Age and fecundability in a North American preconception cohort study. Am J Obstet Gynecol 2017;217(06):667. e1-667.e8. Doi: 10.1016/j.ajog.2017.09.002

2 Menken J, Trussell J, Larsen U. Age and infertility. Science 1986; 233(4771):1389-1394. Doi: 10.1126/science.3755843

3 Lobo RA. Potential options for preservation of fertility in women. N Engl J Med 2005;353(01):64-73. Doi: 10.1056/NEJMra043475

4 Mesen TB, Steiner AZ. Effect of vaginal lubricants on natural fertility. Curr Opin Obstet Gynecol 2014;26(03):186-192. Doi: 10.1097/GCO.0000000000000066

5 Habbema JD, Eijkemans MJ, Leridon H, te Velde ER. Realizing a desired family size: when should couples start? Hum Reprod 2015;30(09):2215-2221. Doi: 10.1093/humrep/dev148

6 Eisenberg ML, Meldrum D. Effects of age on fertility and sexual function. Fertil Steril 2017;107(02):301-304. Doi: 10.1016/j. fertnstert.2016.12.018

7 Dunson DB, Colombo B, Baird DD. Changes with age in the level and duration of fertility in the menstrual cycle. Hum Reprod 2002;17(05):1399-1403. Doi: 10.1093/humrep/17.5.1399

8 Bertoncelli Tanaka M, Agarwal A, Esteves SC. Paternal age and assisted reproductive technologies: problem solver or trouble maker? Panminerva Med 2018; ‘.*;. Doi: 10.23736/S0031-0808.18.03512-7

9 Verón GL, Tissera AD, Bello R, et al. Impact of age, clinical conditions, and lifestyle on routine semen parameters and sperm kinematics. Fertil Steril 2018;110(01):68-75.e4. Doi: 10.1016/j. fertnstert.2018.03.016 
10 Zitzmann M. Effects of age on male fertility. Best Pract Res Clin Endocrinol Metab 2013;27(04):617-628. Doi: 10.1016/j.beem. 2013.07.004

11 Oldereid NB, Wennerholm UB, Pinborg A, et al. The effect of paternal factors on perinatal and paediatric outcomes: a systematic review and meta-analysis. Hum Reprod Update 2018;24(03): 320-389. Doi: 10.1093/humupd/dmy005

12 Practice Committee of the American Society for Reproductive Medicine in collaboration with the Society for Reproductive Endocrinology and Infertility. Electronic address: ASRM@asrm. org; Practice Committee of the American Society for Reproductive Medicine in collaboration with the Society for Reproductive Endocrinology and Infertility. Optimizing natural fertility: a committee opinion. Fertil Steril 2017;107(01):52-58. Doi: 10.1016/j.fertnstert.2016.09.029

13 Dunson DB, Baird DD, Wilcox AJ, Weinberg CR. Day-specific probabilities of clinical pregnancy based on two studies with imperfect measures of ovulation. Hum Reprod 1999;14(07): 1835-1839. Doi: 10.1093/humrep/14.7.1835

14 Bigelow JL, Dunson DB, Stanford JB, Ecochard R, Gnoth C, Colombo B. Mucus observations in the fertile window: a better predictor of conception than timing of intercourse. Hum Reprod 2004;19(04): 889-892. Doi: 10.1093/humrep/deh173

15 Levitas E, Lunenfeld E, Weiss N, et al. Relationship between the duration of sexual abstinence and semen quality: analysis of 9,489 semen samples. Fertil Steril 2005;83(06):1680-1686. Doi: 10.1016/j.fertnstert.2004.12.045

16 Wilcox AJ, Weinberg CR, Baird DD. Timing of sexual intercourse in relation to ovulation. Effects on the probability of conception, survival of the pregnancy, and sex of the baby. N Engl J Med 1995; 333(23):1517-1521. Doi: 10.1056/NEJM199512073332301

17 Jurema MW, Vieira AD, Bankowski B, et al. Effect of ejaculatory abstinence period on the pregnancy rate after intrauterine insemination. Fertil Steril 2005;84(03):678-681. Doi: 10.1016/j. fertnstert.2005.03.044

18 Ayad BM, Horst GV, Plessis SSD. Revisiting the relationship between the ejaculatory abstinence period and semen characteristics. Int J Fertil Steril 2018;11(04):238-246. Doi: 10.22074/ ijfs.2018.5192

19 Kunz G, Beil D, Deininger H, Wildt L, Leyendecker G. The dynamics of rapid sperm transport through the female genital tract: evidence from vaginal sonography of uterine peristalsis and hysterosalpingoscintigraphy. Hum Reprod 1996;11(03):627-632. Doi: 10.1093/HUMREP/11.3.627

20 Settlage DS, Motoshima M, Tredway DR. Sperm transport from the external cervical os to the fallopian tubes in women: a time and quantitation study. Fertil Steril 1973;24(09):655-661. Doi: 10.1016/S0015-0282(16)39908-3

21 Steiner AZ, Long DL, Tanner C, Herring AH. Effect of vaginal lubricants on natural fertility. Obstet Gynecol 2012;120(01): 44-51. Doi: 10.1097/AOG.0b013e31825b87ae

22 Sandhu RS, Wong TH, Kling CA, Chohan KR. In vitro effects of coital lubricants and synthetic and natural oils on sperm motility. Fertil Steril 2014;101(04):941-944. Doi: 10.1016/j.fertnstert.2013.12.024

23 Goldenberg RL, White R. The effect of vaginal lubricants on sperm motility in vitro. Fertil Steril 1975;26(09):872-873. Doi: 10.1016/ S0015-0282(16)41350-6

24 Kutteh WH, Chao CH, Ritter JO, Byrd W. Vaginal lubricants for the infertile couple: effect on sperm activity. Int J Fertil Menopausal Stud 1996;41(04):400-404

25 Anderson L, Lewis SE, McClure N. The effects of coital lubricants on sperm motility in vitro. Hum Reprod 1998;13(12):3351-3356. Doi: 10.1093/humrep/13.12.3351

26 Frishman GN, Luciano AA, Maier DB. Evaluation of Astroglide, a new vaginal lubricant: effects of length of exposure and concentration on sperm motility. Fertil Steril 1992;58(03):630-632. Doi: 10.1016/S0015-0282(16)55279-0
27 Agarwal A, Deepinder F, Cocuzza M, Short RA, Evenson DP. Effect of vaginal lubricants on sperm motility and chromatin integrity: a prospective comparative study. Fertil Steril 2008;89(02):375-379. Doi: $10.1016 /$ j.fertnstert.2007.02.050

28 McSweeney L. Successful sex pre-selection using natural family planning. Afr J Reprod Health 2011;15(01):79-84

29 France JT, Graham FM, Gosling L, Hair P, Knox BS. Characteristics of natural conceptual cycles occurring in a prospective study of sex preselection: fertility awareness symptoms, hormone levels, sperm survival, and pregnancy outcome. Int J Fertil 1992;37(04):244-255

30 France JT, Graham FM, Gosling L, Hair PI. A prospective study of the preselection of the sex of offspring by timing intercourse relative to ovulation. Fertil Steril 1984;41(06):894-900. Doi: 10.1016/S0015-0282(16)47904-5

31 Gray RH, Simpson JL, Bitto AC, et al. Sex ratio associated with timing of insemination and length of the follicular phase in planned and unplanned pregnancies during use of natural family planning. Hum Reprod 1998;13(05):1397-1400. Doi: 10.1093/ humrep/13.5.1397

32 Chiu YH, Chavarro JE, Souter I. Diet and female fertility: doctor, what should I eat? Fertil Steril 2018;110(04):560-569. Doi: 10.1016/j.fertnstert.2018.05.027

33 Byrne J. Periconceptional folic acid prevents miscarriage in Irish families with neural tube defects. Ir J Med Sci 2011;180(01): 59-62. Doi: 10.1007/s11845-010-0629-5

34 Gaskins AJ, Rich-Edwards JW, Hauser R, et al. Maternal prepregnancy folate intake and risk of spontaneous abortion and stillbirth. Obstet Gynecol 2014;124(01):23-31. Doi: 10.1097/ AOG.0000000000000343

35 Hasan R, Olshan AF, Herring AH, Savitz DA, Siega-Riz AM, Hartmann KE. Self-reported vitamin supplementation in early pregnancy and risk of miscarriage. Am J Epidemiol 2009;169(11): 1312-1318. Doi: 10.1093/aje/kwp050

36 Chavarro JE, Rich-Edwards JW, Rosner BA, Willett WC. Use of multivitamins, intake of B vitamins, and risk of ovulatory infertility. Fertil Steril 2008;89(03):668-676. Doi: 10.1016/j.fertnstert.2007.03.089

37 Cueto HT, Riis AH, Hatch EE, et al. Folic acid supplementation and fecundability: a Danish prospective cohort study. Eur J Clin Nutr 2016;70(01):66-71. Doi: 10.1038/ejcn.2015.94

38 Chavarro JE, Rich-Edwards JW, Rosner B, Willett WC. A prospective study of dairy foods intake and anovulatory infertility. Hum Reprod 2007;22(05):1340-1347. Doi: 10.1093/humrep/dem019

39 Møller UK, Streym S, Heickendorff L, Mosekilde L, Rejnmark L. Effects of 250HD concentrations on chances of pregnancy and pregnancy outcomes: a cohort study in healthy Danish women. Eur J Clin Nutr 2012;66(07):862-868. Doi: 10.1038/ejcn.2012.18

40 Somigliana E, Paffoni A, Lattuada D, et al. Serum levels of 25hydroxyvitamin D and time to natural pregnancy. Gynecol Obstet Invest 2016;81(05):468-471. Doi: 10.1159/000443397

41 Zhang H, Huang Z, Xiao L, Jiang X, Chen D, Wei Y. Meta-analysis of the effect of the maternal vitamin $D$ level on the risk of spontaneous pregnancy loss. Int J Gynaecol Obstet 2017;138(03): 242-249. Doi: 10.1002/ijgo.12209

42 Wise LA, Wesselink AK, Tucker KL, et al. Dietary fat intake and fecundability in 2 preconception cohort studies. Am J Epidemiol 2018;187(01):60-74. Doi: 10.1093/aje/kwx204

43 Chavarro JE, Rich-Edwards JW, Rosner BA, Willett WC. Diet and lifestyle in the prevention of ovulatory disorder infertility. Obstet Gynecol 2007;110(05):1050-1058. Doi: 10.1097/01.AOG.0000 287293.25465.e1

44 Chavarro JE, Rich-Edwards JW, Rosner BA, Willett WC. Protein intake and ovulatory infertility. Am J Obstet Gynecol 2008;198 (02):210.e1-210.e7. Doi: 10.1016/j.ajog.2007.06.057

45 Chavarro JE, Rich-Edwards JW, Rosner BA, Willett WC. A prospective study of dietary carbohydrate quantity and quality in relation to risk of ovulatory infertility. Eur J Clin Nutr 2009;63(01):78-86. Doi: $10.1038 /$ sj.ejcn.1602904 
46 Gaskins AJ, Chiu YH, Williams PL, et al; EARTH Study Team. Maternal whole grain intake and outcomes of in vitro fertilization. Fertil Steril 2016;105(06):1503-1510.e4. Doi: 10.1016/j. fertnstert.2016.02.015

47 Chavarro JE, Rich-Edwards JW, Rosner BA, Willett WC. Caffeinated and alcoholic beverage intake in relation to ovulatory disorder infertility. Epidemiology 2009;20(03):374-381. Doi: 10.1097/ EDE.0b013e31819d68cc

48 Abbasi AA, Prasad AS, Rabbani PR. Experimental zinc deficiency in man: effect on spermatogenesis. Trans Assoc Am Physicians 1979; 92:292-302

49 Mitchell M, Bakos HW, Lane M. Paternal diet-induced obesity impairs embryo development and implantation in the mouse. Fertil Steril 2011;95(04):1349-1353. Doi: 10.1016/j.fertnstert.2010.09.038

50 Palmer NO, Bakos HW, Fullston T, Lane M. Impact of obesity on male fertility, sperm function and molecular composition. Spermatogenesis 2012;2(04):253-263. Doi: 10.4161/spmg.21362

51 Palmer NO, Bakos HW, Owens JA, Setchell BP, Lane M. Diet and exercise in an obese mouse fed a high-fat diet improve metabolic health and reverse perturbed sperm function. Am J Physiol Endocrinol Metab 2012;302(07):E768-E780. Doi: 10.1152/ ajpendo.00401.2011

52 Ng SF, Lin RC, LaybuttDR, Barres R, Owens JA, Morris MJ. Chronic highfat diet in fathers programs $\beta$-cell dysfunction in female rat offspring. Nature 2010;467(7318):963-966. Doi: 10.1038/nature09491

53 Morgan DH, Ghribi O, Hui L, Geiger JD, Chen X. Cholesterolenriched diet disrupts the blood-testis barrier in rabbits. Am J Physiol Endocrinol Metab 2014;307(12):E1125-E1130. Doi: 10.1152/ajpendo.00416.2014

54 Rato L, Alves MG, Cavaco JE, Oliveira PF. High-energy diets: a threat for male fertility? Obes Rev 2014;15(12):996-1007. Doi: 10.1111/obr.12226

55 Giahi L, Mohammadmoradi S, Javidan A, Sadeghi MR. Nutritional modifications in male infertility: a systematic review covering 2 decades. Nutr Rev 2016;74(02):118-130. Doi: 10.1093/nutrit/ nuv059

56 Salas-Huetos A, Bulló M, Salas-Salvadó J. Dietary patterns, foods and nutrients in male fertility parameters and fecundability: a systematic review of observational studies. Hum Reprod Update 2017;23(04):371-389. Doi: 10.1093/humupd/dmx006

57 Fullston T, McPherson NO, Zander-Fox D, Lane M. The most common vices of men can damage fertility and the health of the next generation. J Endocrinol 2017;234(02):F1-F6. Doi: 10.1530/JOE-16-0382

58 Augood C, Duckitt K, Templeton AA. Smoking and female infertility: a systematic review and meta-analysis. Hum Reprod 1998;13 (06):1532-1539. Doi: 10.1093/humrep/13.6.1532

59 Camlin NJ, McLaughlin EA, Holt JE. Through the smoke: use of in vivo and in vitro cigarette smoking models to elucidate its effect on female fertility. Toxicol Appl Pharmacol 2014;281(03): 266-275. Doi: 10.1016/j.taap.2014.10.010

60 Anifandis G, Bounartzi T, Messini CI, Dafopoulos K, Sotiriou S, Messinis IE. The impact of cigarette smoking and alcohol consumption on sperm parameters and sperm DNA fragmentation (SDF) measured by Halosperm( $\left({ }^{\circledR}\right)$. Arch Gynecol Obstet 2014;290 (04):777-782. Doi: 10.1007/s00404-014-3281-x
61 Practice Committee of the American Society for Reproductive Medicine. Smoking and infertility: a committee opinion. Fertil Steril 2012;98(06):1400-1406. Doi: 10.1016/j.fertnstert.2012.07.1146

62 Adena MA, Gallagher HG. Cigarette smoking and the age at menopause. Ann Hum Biol 1982;9(02):121-130

63 Aboulmaouahib S, Madkour A, Kaarouch I, et al. Impact of alcohol and cigarette smoking consumption in male fertility potential: Looks at lipid peroxidation, enzymatic antioxidant activities and sperm DNA damage. Andrologia 2018;50(03):e12926. Doi: 10.1111/and.12926

64 Soares SR, Melo MA. Cigarette smoking and reproductive function. Curr Opin Obstet Gynecol 2008;20(03):281-291. Doi: 10.1097/GCO.0b013e3282fc9c1e

65 Sharma R, Harlev A, Agarwal A, Esteves SC. Cigarette smoking and semen quality: a new meta-analysis examining the effect of the 2010 World Health Organization laboratory methods for the examination of human semen. Eur Urol 2016;70(04):635-645. Doi: $10.1016 /$ j.eururo.2016.04.010

66 Anderson K, Norman RJ, Middleton P. Preconception lifestyle advice for people with subfertility. Cochrane Database Syst Rev 2010; ((04):CD008189. Doi: 10.1002/14651858.CD008189.pub2

67 Cinar O, Dilbaz S, Terzioglu F, et al. Does cigarette smoking really have detrimental effects on outcomes of IVF? Eur J Obstet Gynecol Reprod Biol 2014;174:106-110. Doi: 10.1016/j.ejogrb.2013.12.026

68 Steiner AZ, Pritchard D, Stanczyk FZ, et al. Association between biomarkers of ovarian reserve and infertility among older women of reproductive age. JAMA 2017;318(14):1367-1376. Doi: $10.1001 /$ jama.2017.14588

69 Greenwood EA, Cedars MI, Santoro N, et al; National Institutes of Health/Eunice Kennedy Shriver National Institute of Child Health and Human Development Cooperative Reproductive Medicine Network. Antimüllerian hormone levels and antral follicle counts are not reduced compared with community controls in patients with rigorously defined unexplained infertility. Fertil Steril 2017; 108(06):1070-1077. Doi: 10.1016/j.fertnstert.2017.09.015

70 Bozkurt B, Erdem M, Mutlu MF, et al. Comparison of age-related changes in anti-Müllerian hormone levels and other ovarian reserve tests between healthy fertile and infertile population. Hum Fertil (Camb) 2016;19(03):192-198. Doi: 10.1080/ 14647273.2016.1217431

71 Hvidman HW, Bentzen JG, Thuesen LL, et al. Infertile women below the age of 40 have similar anti-Müllerian hormone levels and antral follicle count compared with women of the same age with no history of infertility. Hum Reprod 2016;31(05):1034-1045. Doi: 10.1093/humrep/dew032

72 Hvidman HW, Bang AK, Priskorn L, et al. Anti-Müllerian hormone levels and fecundability in women with a natural conception. Eur J Obstet Gynecol Reprod Biol 2017;217:44-52. Doi: 10.1016/j. ejogrb.2017.08.015

73 Casadei L, Manicuti C, Puca F, Madrigale A, Emidi E, Piccione E. Can anti-Müllerian hormone be predictive of spontaneous onset of pregnancy in women with unexplained infertility? J Obstet Gynaecol 2013;33(08):857-861. Doi: 10.3109/01443615.2013.831050

74 Sominsky L, Hodgson DM, McLaughlin EA, Smith R, Wall HM, Spencer SJ. Linking stress and infertility: a novel role for ghrelin. Endocr Rev 2017;38(05):432-467. Doi: 10.1210/er.2016-1133 